\title{
Language and linguistics
}

\section{LINGUISTIC THEORY See also abstracts 78-160, -166}

78-133 Allan, Keith. Classifiers. Language (Baltimore, Md), 53, 2 (1977), 285-311.

The investigation of data from many languages has the following results: (a) the characteristics of classifier languages are distinguished, and four types are identified; $(b)$ defining criteria are postulated for classifiers, and it is discovered that every classifier is composed of one or more out of seven categories of classification. It is argued that classifiers typically index some perceived characteristic of the phenomenon to which the classification refers, and so the recurrence of similar noun classes in unrelated and geographically separated classifier languages shows that diverse language communities categorise perceived phenomena in similar ways.

78-134 Beard, Robert. On the extent and nature of irregularity in the lexicon. Lingua (Amsterdam), 42, 4 (1977), 305-41.

Several hitherto unconnected lines of research on the nature of lexemic derivation are integrated and focused on the problem of lexical irregularities. A system of derivational typology is developed, which departs from Kurylowicz's distinction of syntactical and lexical derivations, but continues in distinguishing among the latter, those which display sound-meaning symmetry from those which are asymmetrical. Among these latter, two varieties of semantically predictable $v$. unpredictable classes are distinguished: naming and descriptive derivations, then those with and those without verb nexus. Within this framework, the newly emerging theory of redundancy-rule lexicalism is examined and found to be particularly ineffectual in treating asymmetrical derivations.

Asymmetric derivations are shown to have a higher rate of productivity when derivation is seen as a process separate from affixation. Thus a theory incorporating derivation rules in the lexicon and affixation rules in the morphological component will capture more information about lexical regularities than any thus far proposed, without resorting to zero morphemes. Moreover, derivation rules may be used to store the very kinds of unpredictable information for which redundancy rules were designed. Finally, arguments are presented against qualitative differences between sentential and lexemic rules: if lexical rules are properly formulated, the distinction between derivation and redundancy becomes moot. 
78-135 Beryozin, F. M. Советскому языкознанию- 60 лет. [60 years of Soviet linguistics.] Вопросы языкознания (Moscow), 5 (1977), 13-26.

The main achievements of Soviet linguistics over the last 60 years are introduced and discussed. Of particular note are the achievements of Soviet linguists in the fields of sociolinguistics, psycholinguistics and historico-comparative linguistics, quite apart from the enormous amount of work done in the service of the Soviet people. Soviet work on problems concerned with the relationship between thought and speech, language and society, and language typology is especially valuable. Informing all Soviet linguistics is a dialectical-materialist view of language which is superior to bourgeois views. The importance of linguistics as an arena in the continuing ideological war is stressed and Soviet linguists are exhorted to remain abreast of developments in non-Soviet linguistic research, without, however, succumbing to new fashions, since fashion in linguistics is not possible in the context of a dialectical-materialist framework. [Details.]

78-136 Bhat, D. N. S. Multiple case roles. Lingua (Amsterdam), 42, 4 (1977), 365-77.

The meaning distinction introduced by the deletion of certain prepositions like with, in, on, etc. from noun phrases occurring with verbs like blame, spray, load, etc. are shown to be rather similar in kind to that of case relations. It is argued that such meaning distinctions could be explained as resulting from the availability of certain 'multiple case roles' for those noun phrases.

78-137 Filin, F. P. Советское языкознание: теория и практика. [Soviet linguistics: theory and practice.] Вопросы языкознания (Moscow), 5 (1977), 3-12.

The history of Soviet linguistics is characterised by the inter-dependence of theory and practice. Theoretical work has been grounded on Marxist-Leninist philosophy which, despite occasional lapses (e.g. Marr's 'new theory of language' and a certain decline in the fifties) continues to develop successfully. Guided by this philosophy, Soviet theoretical linguistics has made important contributions within sociolinguistics to questions relating to theories of national languages, and language typology, in psycholinguistics to questions relating to the concepts of language and thought and their interrelationship, and in general linguistics has defended a materialist approach while uncovering the theoretical shortcomings and defects of (western) idealistic and generative theories of language which erroneously separate linguistic system and linguistic substance, and relegate the latter, wrongly, to a position of little importance. 


\section{LANGUAGE AND LINGUISTICS}

An enormous amount of work has also been done in the field of applied linguistics, which is a much broader term than structural linguistics. In the decades immediately following the October Revolution an immense amount of work was done in the fields of linguistic description, lexicography, alphabets, writing systems, text-book production and the training of cadres. The sphere of activity has grown rapidly to cover not only the traditional fields of indoEuropean languages, but also non-related language families in all parts of the world. Much of the work in applied linguistics has been of direct relevance to the general cultural development of the Soviet people.

78-138 Nöth, Winfried. Dependenzbeziehungen in der strukturalen Syntax des Englischen. [Dependency relationships in the structural syntax of English.] Lingua (Amsterdam), 41, 3/4 (1977), 239-59.

Within the various models of syntax different approaches are taken toward analysing the relation of dependency. The two main relations of syntactic dependency are determination and interdependence. Within the hierarchical model of the syntactic tree, the relation of dependency is the vertical relation between dominant (higher) and dependent (lower) segments. Interdependence is the vertical relation between segments on the same level of the hierarchy. The basic typological difference which exists between phrase structure grammars (PSG) and dependency grammars (DG) is due to different types of dependency relations. While DGs formalise the relation between nuclear and satellite segments (head and modifier), PSGs formalise the relation between the whole sentence (S) and its parts (NP+VP, etc.). Most structural grammars of English have followed the PSG-approach. Only a few attempts have been made to work out a dependency grammar of English. The different advantages of these two rival models of syntax are discussed. It is argued that the differences between grammars cannot always be evaluated as differences between more adequate and less adequate grammars. It is possible that rival models of syntax have a different adequacy in relation to different aims of description (e.g. recognition grammar $v$. generative grammar) and may thus be complementary.

\section{LANGUAGE AND LOGIC}

78-139 Seidel, Asher. The picture theory of meaning. Linguistics and Philosophy (Dordrecht), 1, 1 (1977), 99-110.

The general features of a picture theory of meaning (PTM) are stated. The PTM is then applied to a particular ontological perspective, and suggestions are made for generalising the PTM to most ontological perspectives. Several ways around the classic problem for the PTM - that the language used to describe a situation 
must have at least one more component than the situation described - are offered.

SEMANTICS See abstract 78-163

DISCOURSE ANALYSIS See also abstracts 78-154, -218

78-140 Good, C. H. Some structural aspects of casual conversation. UEA Papers in Linguistics (Norwich), 4 (1977), 18-45.

The author examines a transcript of casual conversation, considering aspects of the underlying semantics. The account considers the orientation of speakers to social and conversational principles, showing how participants negotiate in verbal activity. Particular features described include the following: chaining principles, the demonstration of parity, and three types of adjacency pairs; 'yes/no question and yes/no answer', 'request and compliance' and 'self-effacing remark and reassurance'. It is argued that relating form to function on a oneto-one basis is not an easy matter, and that the sociological analysis of language should aim to understand conversations as shared 'work'.

\section{COMPUTATIONAL LINGUISTICS}

78-141 Moyne, J. A. The computability of competence. Linguistics (The Hague), 188 (1977), 5-9.

Competence is defined as the knowledge of a mature speaker of a language, irrespective of the controversial questions about methods of acquisition. Can there be an effective procedure? For example, an algorithmic grammar consisting of a precise system of rules, or a Turing machine, for generating sentences of $\mathrm{L}$ as a model of this competence. Neurophysiological developments in automata theory are examined and it is shown that an automaton representing natural phenomena must have at least four random elements: random input, random operations, random structure and random output. This is borne out by recent computational developments in mathematics and computer science. It is therefore hypothesised that there cannot be a precise non-random model for competence. 


\section{SOCIOLINGUISTICS See also abstracts 78-183, -196}

78-142 Baron, Naomi S. Trade jargons and pidgins: a functionalist approach. Journal of Creole Studies (Kappellen, Belgium), 1, 1 (1977), 5-28.

This paper presents a functionalist approach to trade jargons and pidgins which examines the characteristic grammatical structure of these interface languages in the light of the historical situations in which they appeared. It is hypothesised that if language change - including the emergence of new languages - reflects changes in living conditions, then structural differences between trade jargons and pidgins should be predictable from differences in the conditions under which they arose. The two basic variables explored are first, the objects and activities in each original speech community's experience, and second, the relative social and political 'footing' on which the contact groups confront each other. It is suggested that these same variables can be used to explain the historical and temporal distribution of trade jargons and pidgins. [References.]

78-143 Denison, Norman. Language death or language suicide? Linguistics (The Hague), 191 (1977), 13-22.

Anthropomorphic metaphors do not fit language well, but if one uses them, 'language suicide' suggests itself as an alternative to 'language death'. In the stage preceding their disappearance, doomed languages often display a considerable degree of structural and material replacement as a consequence of socially conditioned influence from more vigorous rivals. Evidence is adduced to suggest that this is hardly of itself a cause of demise, and if it is in part describable as 'rule loss' this seems to be fortuitous. More typically, the direct cause of 'language death' is seen to be social and psychological: parents cease transmitting the language in question to their offspring.

78-144 Nadel, Elizabeth and others. English in Israel: a sociolinguistic study. Anthropological Linguistics (Bloomington, Ind), 19, 1 (1977), 26-53.

This study of English in Israel shows that exposure to English is increasing, particularly its study in class and prominence in the mass media. The national language, Hebrew, retains undisputed prominence for conversational, educational and government purposes on the domestic level. English is used increasingly for international communication in various fields. Israel seems to be a crossroad in language development and planning. Although English is recognised as being important, its actual use, such as books read and examination results, is less than might be expected. Current policy is towards increased 
understanding of, and exposure to, English, in addition to Hebrew. Bilingualism in English and Hebrew may become more common than the present multilingualism. [References.]

78-145 Seliger, Herbert W. Biological analogues for language contact situations. IRAL (Heidelberg), 15, 2 (1977), 113-26.

This article proposes that language contact can be best understood if the entire range of such situations is studied within a single framework which is analogical to the symbiosis of living organisms. Language contact can be profitably examined in terms of evolutionary stages that are determined primarily by factors which exist and can change within the total environment of the language contact.

Four types of language symbiosis are described with examples: mutualism, neutralism, competition and commensalism. Particular reference is made to a case of Yiddish/English bilingualism in New York City.

\section{PSYCHOLINGUISTICS}

78-146 Cook, Vivian J. Cognitive processes in second-language learning. IRAL (Heidelberg), 15, 1 (1977), 1-20.

Psycholinguistic research has mainly confirmed the hypothesis that secondlanguage learning is like first-language acquisition, to the extent that other attributes of the mind are not involved, and more precision has been given to some of these attributes. Experiments are described which provided some support for the hypothesis: speech processing memory, which depends on syntax, showed the same type of constraint operating in foreign adults, native adults, and native children; primary memory capacity was most impaired in foreign adults with near-homophones and least impaired with digits; language memory for vocabulary showed the relative lack of clustering of the child rather than the clustering of the adult: the test of the relationship between the concept of time and the sequence of clauses in the sentence produced a more ambiguous result which does not disconfirm the hypothesis.

The complex nature of the interaction between language learning and mental processes makes applications of research to language learning difficult, but it is possible to conclude that the more learning depends on general psychological processes, the less similar first- and second-language learning will be. [References.] 
78-147 Cutler, Anne and Foss, Donald J. On the role of sentence stress in sentence processing. Language and Speech (Hampton Hill, Mddx), 20, 1 (1977), 1-10.

Words bearing high stress appear to be easier to process during sentence comprehension. Since sentence stress typically falls on content words this suggests that comprehension is organised according to a form class bias: process stressed items as content words. The present study measured reaction-time (RT) to word-initial phoneme targets on content and function words in sentence contexts. Half of the words of each type were stressed, half were not. In addition, a variable of 'normality' of stress pattern was manipulated. It was found that RTs were shorter for stressed items independent of their syntactic function. No effect for content vs. function words or normal vs. non-normal stress pattern was observed. Results were interpreted within the framework of a predictive model utilising the concept of semantic focus.

78-148 Fisher, Harwood. From object to image to object. Journal of Psycholinguistic Research (New York), 6, 2 (1977), 105-43.

Images are mental representations accommodated by grammatical structures. These structures order sensori-input of information as well as provide for articulated ways of expressing motor sequences associated with images. The psychological process of perception is reflected in the development of paradigmatic structures. The psychological process of action (behaviour and its mental representations) is reflected in the development of syntagmatic structures. Forming and expressing imagery requires both paradigmatic and syntagmatic structuring. The former relates to logical issues of identity of objects and to the formation of concepts. The latter relates to the solution of psychological questions of causality through articulation of grammatical roles in sentences. Two issues affecting the formation of a model to account for imagery are examined: (1) the tendency to explain imagery as a result of motor sequences and to utilise performance grammar. (2) The impact of ontogenesis on social processes affecting the logical and psychological concerns facing the person at different stages of development. The grammar of imagery is seen as broader than one of performance.

78-149 Rivers, Wilga M. and Melvin, Bernice S. Memory and memorisation in comprehension and production of IP theory. Canadian Modem Language Review (Toronto), 33, 4 (1977), 497-502.

Stimulus-response theory (S-R) neglects 'internal' phenomena such as thoughts, concepts, ideas and emotions. The approach of Information Processing theory (IP), on the other hand, accepts the evidence of common sense and 
builds upon it a rigorous conceptualisation. Memory in the sense of stored experience becomes the core of the model, instead of a superfluity. Adequate description of complex stimuli and responses is required both by the processing routines and for the internal complexity of the concepts they produce or express. [Description of perceptual processing, according to IP, and discussion of Goldman's computer model of the procedural level of production.] The role of memory in production and comprehension is limited to memory in the sense of memorisation (e.g. rule-learning) rather than in the sense of recall. Deeper analysis of the nature of figurative and procedural learning is needed.

\section{LANGUAGE DEVELOPMENT OF CHILDREN See also} abstracts 78-177, -208

78-150 Baron, Naomi S. The acquisition of indirect reference: functional motivations for continued language learning in children. Lingua (Amsterdam), 42, 4 (1977), 349-64.

This paper explores the question of how and why children learn names for things. The acquisition reference is set within a broader discussion of linguistic representation which defines language as a system of symbolscreating a three-way relationship between the individual language user, the world of experience, and the social community. It is argued that the essential function of human language is to allow indirect (rather than direct) reference, and hypotheses are presented on how the child's motivation, his assumptions about what language is for, and his level of linguistic consciousness determine the role of indirect reference in children's learning of names.

In an experiment eliciting indirect reference, four naming strategies were hypothesised: overgeneralisation of a real (but incorrect) name, frustration, description, and made-up names. Twelve Ss between the age of $3 ; 1$ and $4 ; 4$ were presented strange and novel items in picture and object contexts and asked to name those items once the stimuli were removed. The least mature Ss used mostly overgeneralised names. More mature Ss showed some frustration and used both overgeneralisation and description. The most mature Ss showed an increased number of descriptions and used made-up names as well.

78-151 Fluck, Michael J. Young children's comprehension of complex sentences. Language and Speech (Hampton Hill, Mddx), 20, 1 (1977), 48-66.

Studies of children's speech have shown that sentences with subordinate clauses in the subject generally appear later than those with such clauses in the object; this fits Yngve's model of sentence production. However, there are reasons for 


\section{LANGUAGE AND LINGUISTICS}

believing that children must learn to perceive and interpret 'subject' sentences at an earlier age than 'object' sentences. The present study was intended to investigate this and to test specific predictions based on hypothesised processing strategies. The predictions were generally supported and it was shown that children do not acquire a strategy which allows them to interpret 'object' clauses before mental age 7 , whereas a strategy which can handle 'subject' sentences is established before this.

78-152 Kuczaj, Stan A. The acquisition of regular and irregular past tense forms. Journal of Verbal Learning and Verbal Behavior (New York), 16, 5 (1977), 589-600.

The spontaneous speech samples of 15 children were analysed for appropriate use and inappropriate use and non-use of the past tense verbal inflection. Using this data base, the following hypotheses were examined: (1) The irregular past tense form is an earlier acquisition than the regular past tense form. (2) The two types of overgeneralisation errors (goed vs. wented) have acquisition relevance. (3) Partial regularity blocks overgeneralisation errors. (4) The regular rule for the application of -ed is more likely to be overgeneralised to irregular forms such as hit, shut, and put than to other irregular forms. The data provided partial support for the second and third hypotheses, but no support for the first or fourth hypotheses.

78-153 Ramer, Andrya L. H. The development of syntactic complexity. Journal of Psycholinguistic Research (New York), 6, 2 (1977), 145-61.

This longitudinal investigation examined the developmental sequence of syntactic acquisition in seven children during the early syntactic period. The collected corpora were analysed according to a hypothesised simplicity/complexity dimension based on the number of grammatical relations produced and the expansion of these relations. The hypothesised simplicity/complexity dimension was largely upheld and specified a sequence of acquisition which was observed in the data from all children. The application of this dimension, based on the basic grammatical relations, examined developing syntactic complexity independently of but consonant with adult linguistic descriptions. The syntactic constructions were also analysed according to the semantic categories expressed. The semantic analysis revealed generalised developmental trends. 
PHONETICS See also abstracts 78-164, -202

78-154 Pilch, Herbert. Intonation in discourse analysis (with materials from Finnish, English, Alemannic German). Phonetica (Basle), 34, 2 (1977), 81-92.

It is argued that intonation is not additional, but essential to the composition of texts. Even pathological (written) texts can be made to sound normal when read with a good intonation; even well-formed (written) texts cannot be put across when read with a poor intonation; loss of intonation, in aphasia, is coupled with inability to handle texts, and inversely.

Intonation is analysed either as phonological pattern or as a constituent of texts. The lexical meaning of intonations (such as question, statement) is spurious; social tradition makes available certain (spoken) rhetorical topoi for use in standard situations; their use ensures textual meaning. It is not predictable in any given instance.

LEXICOLOGY See abstract 78-134

\section{LEXICOGRAPHY}

78-155 Denisov, P. N. and Skopina, M. A. Научно-методические основы серии. учебных словарей сочетаемости слов pусского языка. [The scientific and methodological bases of a series of learners' word collocational dictionaries of Russian.] Русский язык за рубежсом (Moscow), 4 (1977), 58-62.

A discussion of a theoretical ideal universal dictionary is followed by a description of a dictionary due to appear in 1978, namely a collocational dictionary of Russian for foreign learners. It is classified typologically and its specifications are given. It contains 3,000 words, selected according to comparative frequency and pedagogical relevance, from areas of lexis in the spheres of literature, conversational speech, newspaper language and social science. The selection was finalised in relation to certain criteria including thematic balance, active use in speech, actual linguistic needs of students, postgraduates and teachers of advanced classes, and stylistic unmarkedness. Peripheral collocations have been excluded and typical errors made by foreign students have been taken into account [examples]. Given that it is a learners' dictionary, the amount of grammatical information included is exhaustive and detailed, e.g. all forms of 
the verbs with indications of stress and stress-shifts, exceptions, etc. Particularly detailed are the entries illustrating the most difficult areas of Russian grammar, e.g. verbs of motion, aspectual pairs, and the use of the prepositions.

78-156 Ezquerra, R. Los diccionarios de frecuencia en español (2). [Spanish frequency dictionaries (2).] Boletín de la Asociación Europea de Profesores de Español (Madrid), 10, 16 (1977), 43-54.

A review of Díaz Castañón's Vocabulario básico del español y sus aplicaciones a la enseñanza (1977). This book is not a 'basic vocabulary' in the sense of Français fondamental but a sociolinguistically and situationally coloured survey of the passive vocabulary, essentially the disponible nouns (because of the type of free association test used for elicitation) of schoolchildren of various ages. It has no direct usefulness as a pedagogical tool. [Table comparing the methodology of various Spanish frequency dictionaries. Notes.] [For part 1, see abstract 75-76.]

\section{STYLISTICS}

78-157 Bennett, William A. An applied linguistic view of the function of poetic form. Journal of Literary Semantics (Heidelberg), 6, 1 (1977), 29-48.

The literary critic must analyse before producing the synthesis with which he works. Linguistics offers a means for analysing the language of literary texts. To analyse the language of poetry is to deal with the density of expression which distinguishes it from prose, and yet the techniques are equally relevant to the study of prose literature. One of the main problems in linking linguistics and literary study is the use of the term 'style' [examples and discussion]. For both literary criticism and linguistics there is a need to determine the underlying propositions and their representation in surface structure. The strength of the means of the deeper analysis of texts arises from the structuralist divorce from questions of language use and speech acts. [Example analyses of poems and discussion.]

Language is the beginning and end of literary form. While linguistic analysis may have only a small contribution to make to the critics' armoury, it is an essential part of all literary criticism. [References.] 